\title{
A cradle of reform
}

\author{
Nick Black
}

J R Soc Med 2007; 100:175-179

This is the third of four articles that provides the background to one of the walks in a new book, Walking London's Medical History, which aims are to tell the story of how health services developed, to help preserve our legacy of buildings and to inform current debates about health care. Walking London's Medical History is available from the RSM Press website: http:// www.rsmpress.co.uk/bkblack2.htm

While health services are always changing, the middle decades of the 19th century were an extraordinarily active period of reform. And in England, one small area of London, St Pancras and Bloomsbury_-bounded by Euston Road in the north, Gray's Inn Road in the east, Great Ormond Street in the south and Russell Square in the west - was to prove exceptionally influential.

Between 1740 and 1840, as London spread north, the rural tranquillity of this area was replaced by terraced streets and squares. At that time, the only hospitals in the area were for those suffering infectious diseases (the London Smallpox Hospital and the London Fever Hospital) and for abandoned infants (the Foundling Hospital). Despite this, during the early decades of the 19th century, leading doctors and medical organizations had made the area just to the south, in Holborn, the centre of 'medical London'.

It may simply have been a coincidence that so many revolutionary changes emanated from this area between 1840 and 1880. But more likely the area attracted and accommodated reformers determined to challenge established ways and develop new health services, just as it has attracted reformers in fields as diverse as the penal system, adult education, literature and painting. A walk through this area reveals how, in a 40 year period, health care in England was radically altered by events that took place here. The highlights of the walk are shown in Box 1.

\section{CONCERN FOR THE NEGLECTED}

The pace of change between 1840 and 1880 was remarkable. Its focus was concern for those who had traditionally been ignored: children, who had largely been excluded from hospitals until the development of the Hospital for Sick Children (Box 2) and the Alexandra

Professor of Health Services Research, London School of Hygiene \& Tropical Medicine, Keppel Street, London WC1E 7HT

E-mail: nick.black@Ishtm.ac.uk

\section{Box 1 Highlights of the walk}

- Largest Ear, Nose and Throat hospital in the world (Royal Nose, Throat \& Ear Hospital)

- Most radical, innovatory teaching hospital in England in the 19th century (Royal Free Hospital)

- One of the leading children's hospitals in the world (Great Ormond Street Hospital)

- Largest homoeopathic hospital in Britain (Royal London Homeopathic Hospital)

- Hospital for Italians (Ospedale Italiano)

- Leading hospital for nervous diseases in Britain (National Hospital for Neurology \& Neurosurgery)

- Remains of the first foundling hospital in Britain

- First medical school for women in Britain

- Only hospital for women, staffed by women in Britain (Elizabeth Garrett Anderson Hospital)

Hospital; the destitute poor (including those forced into prostitution), for whom the doors of the Royal Free Hospital (Box 3) were open; the aged and decrepit, cared for by the Hospital for Infirm and Incurable Women, the Hospital of St John \& St Elizabeth, and Louisa Twining's Nursing Home for the Elderly \& Epileptics; the paralysed and epileptic for whom the Hospital for the Paralysed \&

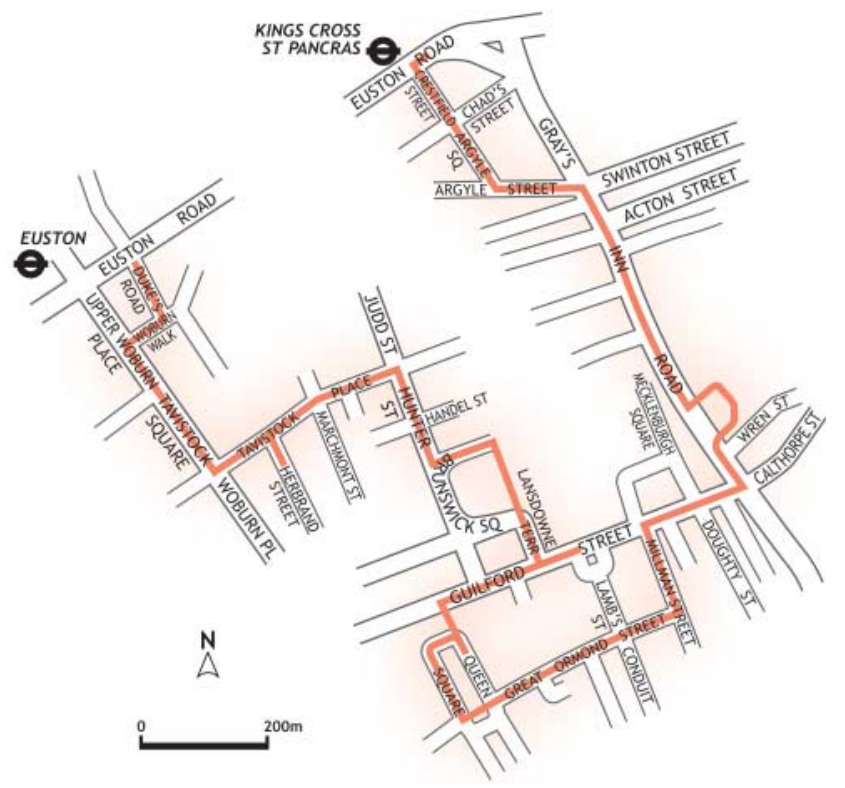

Figure 1 A map of the route 


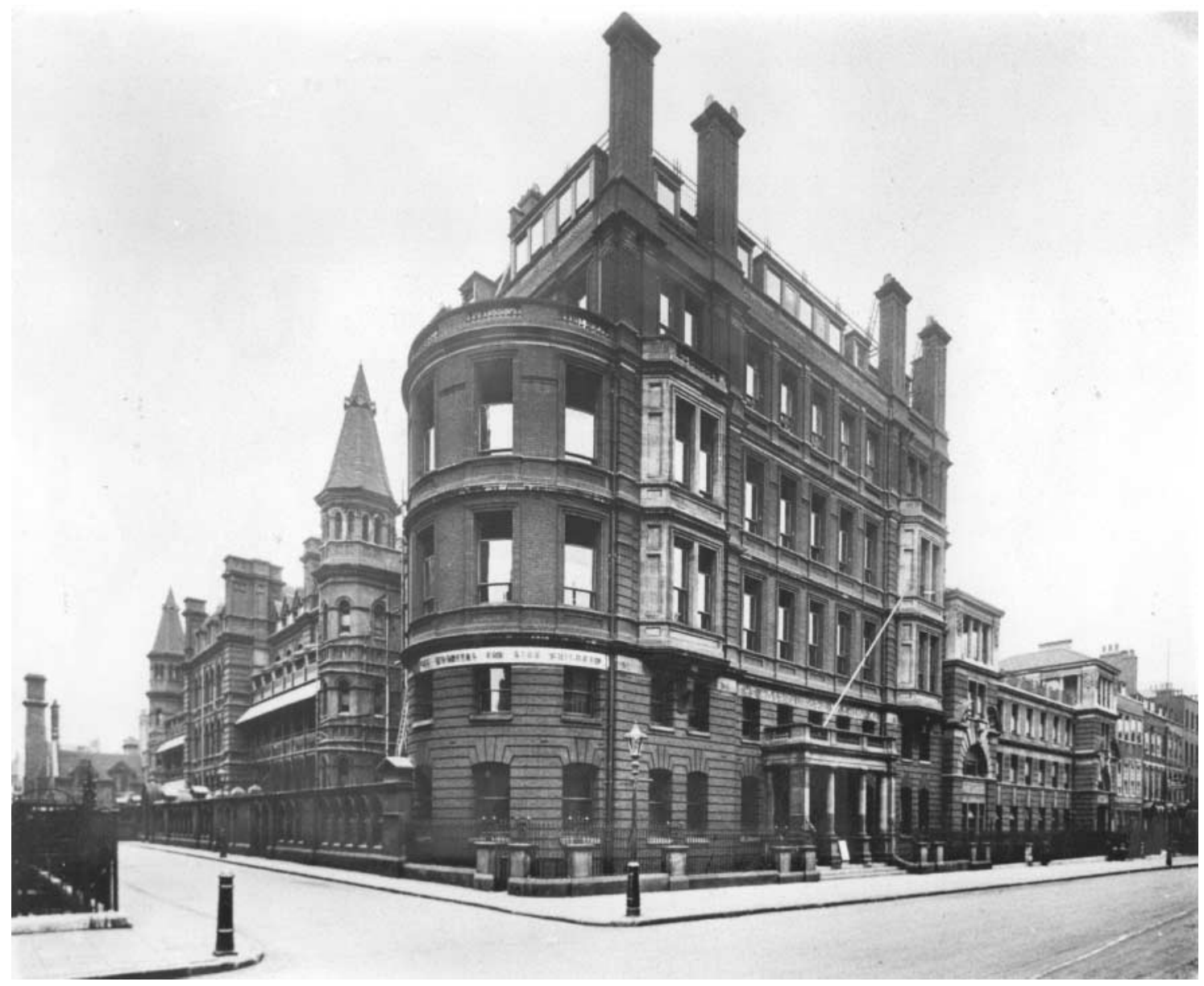

Figure 2 The 'Hospital in the Gardens' extending along Powis Place was designed by Edward Barry in 1875 for the Hospital for Sick Children. The southern wing (on Great Ormond Street in the foreground), designed by his brother, Charles, was not completed until 1893 and is all that survives.

\section{Box 2 Hospital for Sick Children}

Until the middle of the 19th century, there was little hospital care available for children. Despite half of all deaths occurring in childhood and several books on childhood diseases having been published in the 18th century, children made up only $6 \%$ of inpatients in the voluntary general hospitals in London. Lack of hospital provision was justified on the grounds that the care of children was best left to mothers. Indeed, many believed it would be wrong to separate children from mothers by admitting them to hospital. This was in sharp contrast to European neighbours: the Hopital des Enfants Malades had been established in Paris in 1802 and similar institutions existed in Germany, Italy, Russia, Austria, Denmark and Turkey.

In 1849 Charles West resigned as a physician at one of the few dispensaries devoted to children, the Universal Dispensary for Children in Waterloo, and galvanized a group of aristocrats, including Lord Byron's wife and daughter and Lord Shaftesbury, to raise funds for a children's hospital. No 49 Great Ormond Street was purchased and the Hospital for Sick Children opened in 1852. The trepidation of mothers to bring their sick children was not to be easily overcome. It was to be the social reformer Charles Dickens who, writing in the popular magazine Household Words, provided the reassurance mothers sought.

The need to expand led to the purchase of No 48 next door. Both houses had large gardens which in 1875 provided the land for the construction of Edward Barry's 'Hospital in the Gardens', a Victorian red brick gothic building which included a Byzantine-style chapel (Figure 2). All that remains of the building, which faced onto Powis Place, is the south wing and the chapel, which was moved $18 \mathrm{~m}$ on hydraulic skates over the course of two days in the 1990s.

During the 20th century the hospital steadily expanded. In 1908, the neighbouring two houses in Great Ormond Street were bought and demolished to make way for a new outpatient department. A suggestion in 1920 to create a 'country hospital city' 30 miles from London failed to materialize. Instead, in Powis Place, the north wing of Barry's building made way in 1938 for a huge new building along the northern side of the site, the Southwood Building, which had extensive balconies for nursing children in the open air. Another portion of the Barry building was demolished in the 1990s to make way for a large new building extending through the centre of the site. 
Epileptic was created (Box 4); pregnant women, largely excluded from general hospitals until the Royal Free Hospital established an obstetric service; and foreigners (for example Italians, for whom the Ospedale Italiano was established).

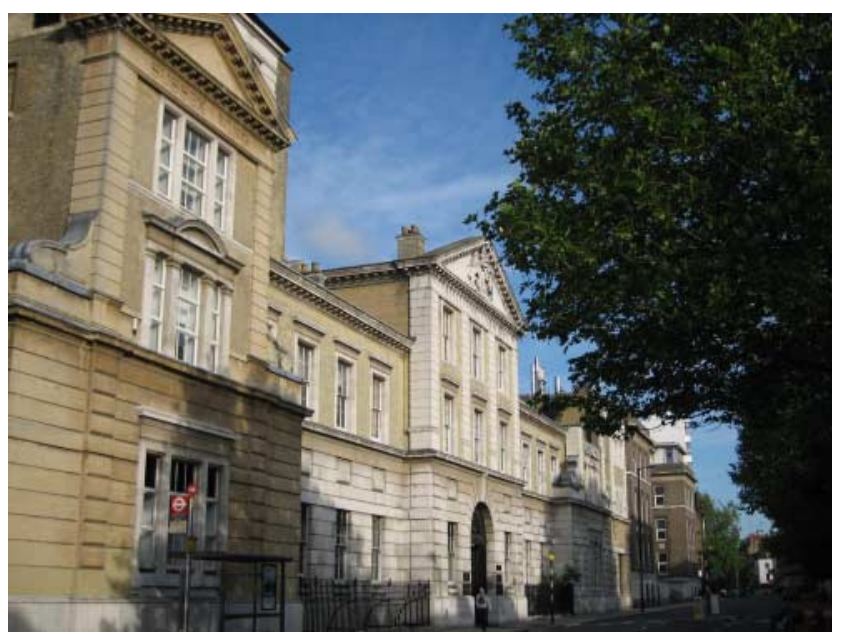

Figure 3 The three main wings of the former Royal Free Hospital from left to right: the end of the Sussex wing (1856); Alexandra wing, containing the main entrance (1893); and the end of Victoria wing (1876). [In colour online.]

\section{Box 3 Royal Free Hospital}

\section{NEW OPPORTUNITIES FOR STAFF}

It wasn't only patients who experienced the benefits of reform. This area was also the birthplace of new opportunities for health-care staff. It was here that women finally succeeded in storming the male medical establishment by creating the first medical school open to women, the London School of Medicine for Women, and persuading a general hospital, the Royal Free, to provide clinical training for its students. And it was fitting that the first purpose-built women's hospital staffed entirely by women, the New Hospital for Women, was established here (Box 5). Conversely, the Hospital for the Paralysed \& Epileptic was one of the first hospitals to employ male nurses in what had been an exclusively female occupation. The area also provided a home for a group of alternative practitioners that the medical establishment wanted outlawed in the 1850s, homeopaths. And the introduction of Lady Almoners (similar to modern-day hospital social workers) occurred here, in the Royal Free Hospital.

\section{OTHER THEMES}

Alongside these major reforms, this walk also illustrates several other themes. First, the impact of the railways which both forced institutions to move as they were granted priority for land (London Smallpox Hospital; London Fever

In 1828 voluntary general hospitals required patients to have a letter of recommendation from a subscriber to gain admission. William Marsden, a surgeon, finding a young girl dying of disease and hunger on the steps of a Holborn church who had been refused admission at three hospitals, determined to establish a hospital 'to which the only passport should be poverty and disease.' He established the London General Institution for the Gratuitous Cure of Malignant Diseases in Hatton Garden. Unlike many hospitals, it remained open during the cholera epidemic. In 1833 it was renamed the London Free Hospital, and four years later, having received Queen Victoria's endorsement, it acquired its permanent title Royal Free Hospital. It was to be the most radical and innovatory of the 12 London teaching hospitals, reflecting the motivation and aim of its founder.

In 1842, the governors acquired the lease on the abandoned barracks of the Light Horse Volunteers in Gray's Inn Road. Over the following 50 years the buildings, designed for accommodating horses, were replaced or enhanced (Figure 3).

The hospital's commitment to Marsden's radicalism can be seen in several ways. First, by its provision of care to those in need irrespective of their circumstances: it treated people that other hospitals turned away. A subscriber's letter was not needed, patients with venereal disease were accepted, and as a consequence prostitutes were admitted. Second, in 1877, it agreed to provide clinical teaching to students from the nearby London School of Medicine for Women. Apart from a brief period during WWI, it was the only hospital in London to accept female medical students before 1947.

Third, in 1895 it was the first hospital to appoint a Lady Almoner, Miss Mary Stewart, whose job was 'to ensure that patients in poor circumstances were helped to benefit from treatments recommended by medical staff and to prevent the abuse of the hospital by persons able to pay for medical treatment.' Although she focused more on the former than the latter, the public perceived her as a threat, attempting to collect money, and the doctors resented her 'interference' in patient selection. Despite this, she became known as 'Lady Harmony', and over the following eight years six other hospitals appointed a Lady Almoner, all of whom were 'trained' by Mary Stewart.

Fourth, in 1918 it was the first voluntary general hospital in modern times to provide lying-in care for childbirth. And all these innovations were made despite it being the poorest of the 12 teaching hospitals in London.

After WWII, the drive to move some teaching hospitals out of central London gathered pace. After much discussion, it was decided to rebuild the Royal Free in Hampstead, a move that eventually took place in 1974. The old building was taken over in 1988 by the Eastman Dental Hospital, which had started as the dental department of the Royal Free Hospital. 


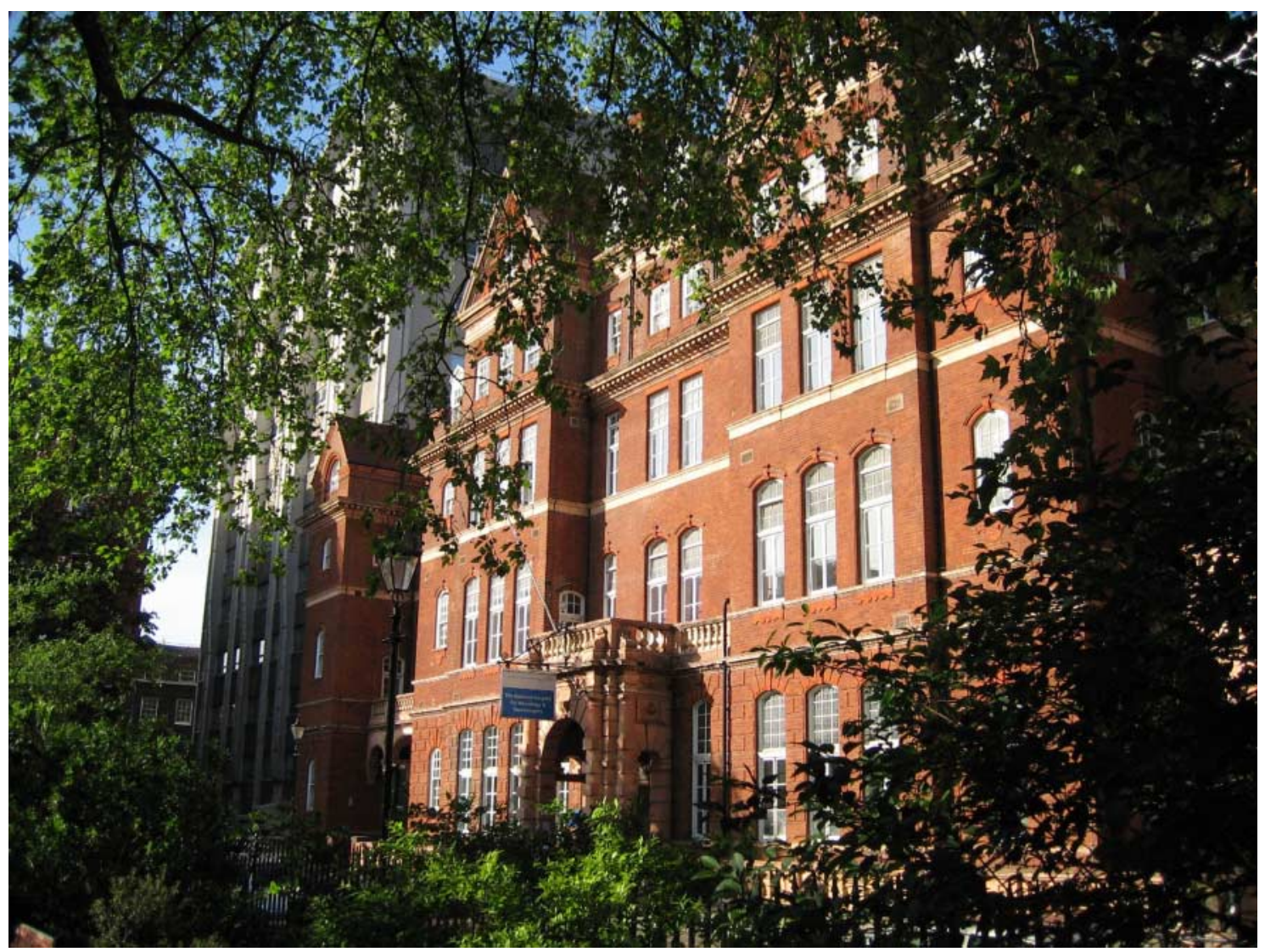

Figure 4 National Hospital for the Paralysed \& Epileptic was established in $\mathbf{1 8 6 0}$ in houses on this site which were replaced by this fine building in 1885. The Institute of Neurology's modern tower block can be seen beyond it. [In colour online.]

\section{Box 4 National Hospital for Neurology \& Neurosurgery}

Before the middle of the 19th century there were no facilities for the care and treatment of those with neurological conditions causing paralysis and epilepsy. The lack of medical interest in such conditions reflected fear and ignorance, the absence of any effective treatments, and the impoverished state of many sufferers making this an unprofitable area in which to specialize. Until the Poor Law was amended in 1867, epileptics and the paralysed were consigned to the 'insane' wards of workhouses. It is therefore not surprising that, unlike almost all other specialist hospitals and dispensaries, the first institution devoted to the paralysed and epileptic was founded, not by doctors but by lay people-Johanna, Louisa and Edward Chandler-who had cared for their paralysed grandmother.

The National Hospital for the Paralysed \& Epileptic opened in two houses on this site in 1860, with space for 36 inpatients and providing therapies based on water and on electricity. It was not universally welcomed by its neighbours, who objected to patients walking or sitting in the gardens. In response, patients took chairs and sat at the end of the square outside the railings of Queen Square House, much to the displeasure of the resident, the Lord Chief Justice.

The key role of lay people in its foundation continued in its management, with the attendant tensions between lay governors and medical staff. The former were adamant that if doctors were included in management 'the hospital would be in danger of having the philanthropic aspect of its work subordinated to that which is merely scientific and investigatory,' concerns that resonate with some politicians and patient organizations today. There is some suggestion that the governors' fears were well-placed. In 1869, a visiting German doctor, Dr Pelman recognized the hospital was 'a pure jewel-case . . . containing beautiful baths of every kind, including, naturally, a Turkish bath; a spacious room very richly equipped with electrical fittings, and an impressive gymnasium' but observed that it was not apparent that 'bad epileptics or unclean paralytics' were admitted.

The hospital expanded both laterally and onto land behind the houses. In 1885 the houses were replaced with a fine red-brick building (Figure 4). It continued to thrive and, in 1938, the Rockefeller Wing was built alongside.

With the start of the NHS, it became the National Hospital of Nervous Diseases and the University of London located the Institute of Neurology here. The hospital changed to its current name, recognizing the surgical aspects of its services, in 1988. 
In 1866, having exploited a loophole in the regulations of the Society of Apothecaries, Elizabeth Garrett registered as a medical practitioner. Facing hostility from the male medical establishment and unable to gain employment in any existing hospitals or dispensaries, she established St Mary's Dispensary for Women in Marylebone, staffed by women. It became the New Hospital for Women in 1872, when it moved to Marylebone Road where 26 beds were provided.

The success of her hospital led to another move in 1890 to custom-built premises on Euston Road (Figure 5). The hospital, with 42 beds, aimed to be homely: central heating, polished parquet floors, open fires 'just to look at' and old brown milk jugs full of flowers. The original entrance on Euston Road has long since been removed. Following her death in 1917, the hospital was renamed the Elizabeth Garrett Anderson Hospital (she had married a Mr Anderson in 1893) and a rather unprepossessing wing was added in 1929.

The founding ethos of the hospital was maintained when it joined the NHS in 1948. Indeed, the hospital had to gain exemption from the 1975 Sex Discrimination Act to continue its policy of female-only staff. Although it had grown to 161 beds, this was increasingly seen as being too small for a general hospital. So in 1979 it limited its work to gynaecology, in keeping with its original mission. However, the pressure for merger was unrelenting. In 1989 the Hospital for Women moved from Soho to share the building.

Significantly, this brought male doctors onto the staff for the first time. Its geographical isolation still concerned people and in 2001 it merged with the obstetric department of University College Hospital to form the Obstetrical \& Elizabeth Garrett Anderson Hospital in Huntley Street (near the main hospital).

The building's connection with health-care looks like continuing. In 2005, the trades union UNISON acquired it and plans to convert it to their new headquarters. Given that the union represents many low paid women working in health care, part of the ethos of the building's original occupants will live on.

Hospital; Great Northern Hospital) and increased the accessibility of hospitals to those living outside London. Hospitals sited near stations, such as the Royal National Throat, Nose \& Ear Hospital, gained an advantage over competitors.

The second theme of the walk is the often tricky relationship between doctors and managers. There was a striking contrast between hospitals in which doctors

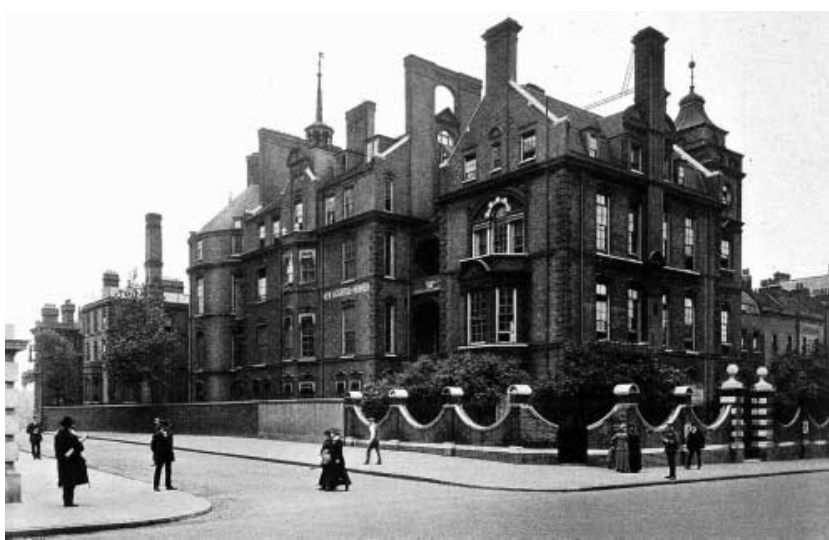

Figure 5 New Hospital for Women, built in 1890, with its main entrance on Euston Road and state-of-the-art circular wards at the rear. It was abandoned in 2001 and awaits restoration.

participated and accepted some managerial responsibility (Royal National Throat, Nose \& Ear Hospital; Royal Free Hospital; London Fever Hospital) and those in which lay governors excluded doctors from management (Ospedale Italiano; National Hospital for the Paralysed \& Epileptic). In the latter, tensions even led on occasions to mass medical resignations.

Third, the importance of international influences on health care: the introduction of smallpox inoculation from Turkey; the establishment of foundling hospitals modelled on those in Italy, Austria and Russia; the introduction of homoeopathy from Germany; the creation of children's hospitals, copying those in France, Germany and Turkey; the training and employment of women doctors which already occurred in Italy, Germany and France; and the introduction of post-graduate education for doctors, already well-established in Vienna and other European cities.

And finally, not all hospitals were founded by male doctors. Some of the key developments in health services were instigated by women doctors (Elizabeth Garrett's establishment of the New Hospital for Women), by nurses (Catherine Wood and colleagues who established the Alexandra Hospital) and by lay people (the Chandler siblings founded the National Hospital for the Paralysed \& Epileptic; Giovanni Ortelli founded the Ospedale Italiano; and Cardinal Wiseman created the Hospital of St John \& St Elizabeth). 